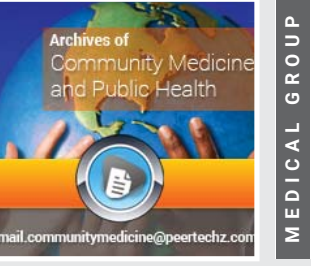

\title{
The experience of living with diabetes mellitus
}

\section{Percis P Khumalo1*, Mirriam Sebego², Cynthia Z Vilakati ${ }^{3}$, Mildred SP Mkhabela ${ }^{4}$ and Tengetile R Mathunjwa-Dlamini ${ }^{5}$}

${ }^{1} \mathrm{MNSc}, \mathrm{RN}$ is a Lecturer at the Faculty of Health Sciences, University of Swaziland, Mbabane, Swaziland, Southern Africa

${ }^{2} \mathrm{PhD}, \mathrm{RN}$ is a Lecturer at the Faculty of Health, University of Botswana, Southern Africa

${ }^{3} \mathrm{MA}$ Cur, RN is a Lecturer at the Faculty of Health Sciences, University of Swaziland, Mbabane, Swaziland, Southern Africa

${ }^{4} \mathrm{PhD}, \mathrm{RN}$ Lecturer at the Faculty of Health Sciences, University of Swaziland, Mbabane, Swaziland, Southern Africa

${ }^{5} \mathrm{PhD}, \mathrm{RN}$ is an Associate Professor at the Faculty of Health Sciences, University of Swaziland, Mbabane, Swaziland, Southern Africa
Received: 06 October, 2021

Accepted: 21 October, 2021

Published: 22 October, 2021

*Corresponding author: Percis P Khumalo, MNSc $\mathrm{RN}$ is a Lecturer at the Faculty of Health Sciences, University of Swaziland, Mbabane, Swaziland, Southern Africa, Tel: 268-2517-0700; Fax: 268-2517- 0701; E-mail:pkhumalo@uniswa.sz

Keywords: Diabetes mellitus; Physiological effects; Psychological effects; Self-care

Copyright: (c) 2021 Khumalo PP, et al. This is an open-access article distributed under the terms of the Creative Commons Attribution License, which permits unrestricted use, distribution, and reproduction in any medium, provided the original author and source are credited.

https://www.peertechzpublications.com

\section{Check for updates}

\begin{abstract}
Diabetes mellitus is one of the chronic complex diseases which affect the physiological, social and psychological aspects of life, interfering with the functional health status of clients. As a chronic disorder, diabetes mellitus is a lifelong condition. The purpose of the study was to explore experiences of people living with type 2 diabetes mellitus at the Mbabane Government Hospital, Swaziland. The study utilized a qualitative exploratory design. Purposive sampling was used to select the participants. The sample size of 12 participants was determined by data saturation. A thematic data analysis was used. The themes that emerged were physiological, psychological; socio-economic and self-management effects of living with diabetes mellitus. The study findings call for empowerment of people suffering from diabetes mellitus with knowledge and skills on self-management, prevention and early detection of complications.
\end{abstract}

\section{Introduction}

Diabetes mellitus is the most common non-communicable disease and a major public health challenge with increasing incidence in many emerging countries in the world [1]. Diabetes mellitus is the third leading cause of death that affects human populations worldwide and poses major public health and socioeconomic issues [2]. In 2013, an estimated 382 million adults worldwide were living with diabetes mellitus, and projections suggest that more than 592 million adults will have the disease by 2035 [3]. According to Gambert \& Pinkstaff [4] diabetes mellitus is one of the world's fastest growing chronic health illnesses that affect almost every aspect of life e.g. physically, psychologically, socially, spiritually and economically [4]. Kneck [5] defined a chronic illness as a condition or disease that is persistent and lasts for more than three (3) months. The world is in the midst of this disease, which if not controlled will produce an unbearable burden on quality of life (International Diabetes Federation (IDF) [6].
The American Diabetes Association (American Diabetes Association [ADA], [7] had defined diabetes mellitus as a group of metabolic diseases characterized by an increased blood glucose level in the body. The increased blood glucose is caused by a decrease or lack of ability to produce insulin or to effectively use the insulin produced. The blood glucose causes serious damage to the nerves and blood vessels resulting in diabetes-related complications such as visual, cardio-vascular, and kidney disorders. There are four (4) major classifications of diabetes mellitus; type 1 , type 2 , secondary, and gestational diabetes mellitus [8].

Type 1 Diabetes Mellitus (T1DM) is sometimes referred to as juvenile diabetes mellitus which may occur as a result of auto immunity whereby; there is progressive destruction of beta cells due to auto immunity among susceptible individuals [8]. Autoantibodies to islet cells destroy $80-90 \%$ of normal beta cell function before hyperglycaemia and other manifestations of diabetes mellitus occur. T1DM appears when there is no 
more insulin secretion. This type of diabetes mellitus requires exogenous insulin in order to sustain the individuals' life [8].

Type 2 Diabetes Mellitus (T2DM) also known as adult onset diabetes mellitus could occur as a result of genetic mutation which causes body tissue resistance to insulin (body does not respond to action of insulin) [8]. The insulin receptors are either unresponsive to the action of insulin and / or the insulin secreted is inadequate. Individuals living with T2DM require oral hypoglycaemics in order to control their glucose level. Secondary diabetes mellitus is the type of diabetes mellitus that is associated with other medical conditions / treatment of conditions such as endocrinopathies (acromegally, hyperthyroidism, and Cushing's syndrome), pancreatic disease (pancreatectomy, cystic fibrosis). It could also occur following the use of medication, such as thiazides, corticosteroids, phenytoin and clozapine [8]. Gestational diabetes mellitus is the type of diabetes mellitus that occurs in pregnancy. Women with gestational diabetes mellitus are reported to be at a higher risk of developing T2DM in $5-10$ years [8]. This study focused on T2DM.

According to the ADA [7], the risk of developing T2DM increases with age, obesity and inactivity. T2DM is also more common in people with a family history of the disease. The disease develops gradually over a long period of time, with vague symptoms or none at all. George and Thomas [9] on the other hand, reported that the socioeconomic and lifestyle factors also appeared to be high risk factors of developing diabetes mellitus especially among individuals who reside in rural areas. People in rural areas are usually poor and may have limited access to health care and consequently are likely to be diagnosed late compared to their urban counterparts.

\section{Problem statement}

According to the ADA [7], diabetes mellitus has become a worldwide health problem in the $21^{\text {st }}$ century. In the United States of America (USA) over 23 million people are currently diagnosed with diabetes mellitus and an estimated 225,000 deaths are reported annually. In the Sub-Saharan Africa, diabetes mellitus was thought to be a rare or undocumented disease. However, ADA [7] reported that in 2004 there was a shift of non-communicable diseases including diabetes mellitus in this region. Diabetes mellitus emerged with an estimated 3.4 million deaths and more than $80 \%$ of these deaths occurred in low and middle income countries.

Swaziland much like most developing countries in the SubSaharan Africa region is not spared from this epidemic of noncommunicable diseases such as diabetes mellitus. Swaziland has an estimated prevalence of diabetes mellitus at 3.7\% among those aged between 20 and 79 years. This prevalence was above the $3.2 \%$ average prevalence of diabetes mellitus in Africa [6]. The IDF [6] also found that Swaziland had an estimated 20,800 people aged between 20 - 79 years who suffered from diabetes mellitus and about 1,146 people died each year from complications related to diabetes mellitus.

The World Health Organization (WHO) [10]; IDF (2008); Swaziland STEPS Survey [11] revealed that the main cause of diabetes mellitus in Swaziland among the adult population aged between 20-79 years, were factors such as physical inactivity, sedentary lifestyle and low consumption of fruits and vegetables. An estimated $89 \%$ of the adult population was found to be consuming less than an average of 5 vegetables per day. Obesity and overweight were found to be more prevalent among female compared to male adults. Moreover, hypercholesterolemia and triglycerides were more prevalent in adult males than females. These findings suggest that the adult population in this country is at an increased risk of developing T2DM. There is limited documentation on experiences of people living with T2DM in Swaziland. Hence this study which explored the experiences of people living with diabetes mellitus. The findings will enable the country in developing targeted and relevant interventions.

\section{Research question}

1. What are the experiences of people living with T2DM?

\section{Objective of the study}

2. To explore experiences of persons living with T2DM attending services at the Mbabane Government Hospital

3. To identify concerns of people living with diabetes mellitus as a chronic illness.

4. To identify challenges in the management of T2DM in people living with the disorder.

\section{Methodology}

The study utilized the descriptive qualitative approach. It was conducted at the Mbabane Government Hospital, Swaziland. The Mbabane Government Hospital is a national referral hospital situated in Mbabane which is the capital city of Swaziland. It has a bed capacity of 440 . This hospital functions as both a tertiary and national referral institution, and serves more than 95000 population that resides around the city $[12,13]$.

Purposive sampling was used to select study participants. The sample size was determined by data saturation. The participants were aged between 49-79 years, either male or female, diagnosed with T2DM for more than a year and on a subsequent visit at the Mbabane Government Hospital diabetes clinic.

Ethical approval was sought from the Ministry of Health Scientific and Ethics Committee, Mbabane Government Hospital authorities, and the participants. An in-depth interview guide was used to collect data. Thematic analysis was used in evaluating the data.

\section{Results}

The findings are presented in a narrative form, with periodic inclusion of direct verbal quotations from participants to emphasize facts and offer the reader evidence of what emerged during data collection. The findings begin with a description of the socio-demographic characteristics of the participants, before a comprehensive presentation of the themes that emerged from the data analysis are presented. 


\section{Socio-demographic characteristics of the participants}

There were 11 participants in the study. The sample size was determined by data saturation, which is characteristic of qualitative studies. Sixty four percent $(64 \%, n=7)$ of the participants were males and $36 \%(n=4)$ were females. The ages of the participants ranged between 52 and 80 years, with the majority $(55 \%, \mathrm{n}=6)$ aged between 52 and 60 years. The mean age of the participants was 64.1 years with a standard deviation of 9.7 years. All participants $(n=11,100 \%)$ reported that they attended school, 36\% $(n=4)$ had primary, $46 \%(n=$ 5) had secondary, and $18 \%(n=2)$ had tertiary level education. The majority $(55 \%, n=6)$ of the participants reported that they were unemployed, $27 \%(n=3)$ were retired and only $18 \%(n=$ 2) were employed. All the participants were Swazis, married, and their religious affiliation was Christianity. The participants had lived with diabetes mellitus for a mean period of 8.3 years and a standard deviation of 5.4 years. The majority $(64 \%, n$ = 7) of the participants reported to have lived with diabetes mellitus for less than 10 years, and $36 \%(n=4)$ had lived with the disorder for more than 10 years. The socio-demographic characteristics of the participants are summarized in Table 1.

\section{Themes}

Numerous themes emerged from the data. These themes were the true indication of the clients' experience of living with T2DM. Themes reflecting the participants' experiences were: physiological, psychological, socioeconomic, and selfmanagement effects of T2DM. The code categories and themes are illustrated in Table 2.

\section{Physiological effects of living with diabetes mellitus}

The participants reported poor vision, neuropathy and comorbidity as main problems affecting them on the physiological effects of living with T2DM. The categories are discussed separately.

a. Diabetic retinopathy: Poor eye sight was found to be the major consequence of living with diabetes mellitus.

Table 1: Demographic characteristics of participants $(\mathrm{N}=11)$

\begin{tabular}{|c|c|c|c|c|c|c|c|}
\hline $\begin{array}{l}\text { Code } \\
\text { No: }\end{array}$ & Gender & Age (yrs) & $\begin{array}{l}\text { Marital } \\
\text { status }\end{array}$ & $\begin{array}{c}\text { Educational } \\
\text { status }\end{array}$ & $\begin{array}{c}\text { Employment } \\
\text { status }\end{array}$ & Religion & $\begin{array}{c}\text { Duration } \\
\text { with DM } \\
\text { (yrs) }\end{array}$ \\
\hline 01 & M & 72 & Married & Secondary & Retired & Christian & 17 \\
\hline 02 & M & 65 & Married & Secondary & Retired & Christian & 10 \\
\hline 03 & $\mathrm{~F}$ & 52 & Married & Tertiary & Employed & Christian & 5 \\
\hline 04 & $\mathrm{~F}$ & 59 & Married & Primary & Unemployed & Christian & 7 \\
\hline 05 & $\mathrm{~F}$ & 56 & Married & Primary & Unemployed & Christian & 3 \\
\hline 06 & $\mathrm{~F}$ & 56 & Married & Primary & Unemployed & Christian & 7 \\
\hline 07 & M & 80 & Married & Primary & Unemployed & Christian & 10 \\
\hline 08 & M & 60 & Married & Secondary & Retired & Christian & 5 \\
\hline 09 & M & 80 & Married & Secondary & Unemployed & Christian & 20 \\
\hline 10 & M & 54 & Married & Tertiary & Employed & Christian & 3 \\
\hline \multirow[t]{3}{*}{11} & M & 71 & Married & Secondary & Unemployed & Christian & 4 \\
\hline & & $\bar{x}=64.1$ & & & & & $\bar{x}=8.3$ \\
\hline & & $S D=9.7$ & & & & & $S D=5.4$ \\
\hline
\end{tabular}

Table 2: Categories and themes of living with diabetes mellitus.

\begin{tabular}{|c|c|}
\hline Categories & Themes \\
\hline $\begin{array}{c}\text { Diabetic retinopathy } \\
\text { Diabetic neuropathy and pain } \\
\text { Comorbidity }\end{array}$ & Physiological effects \\
\hline Sexual dysfunction & Psychological effects \\
\hline $\begin{array}{c}\text { Financial support and costs } \\
\text { Travelling long distance } \\
\text { Treatment adherence } \\
\text { Long waiting time } \\
\text { Knowledge }\end{array}$ & Socioeconomic impact \\
\hline
\end{tabular}

Participants reported a gradual loss of eyesight in such a way that performing activities of daily living was becoming a nightmare.

One participant had this to say: "... apart from what I have said... in addition... the sugar has affected me... and my eyes..., (pointing at his eyes) like at night, I cannot drive especially when I have to meet with other cars. It is a problem, it is better when I do not meet with other cars... I can say that... that affects me".

Another one had this to say: "when I first had sugar, I had a problem of not seeing well with my eyes... almost one month.. and I went to the clinic and I was told that my eyes are not damaged... and they would gain sight... and it happened like that ... and I was told to wear glasses".

Another one said: "I do not see properly... that is the major problem I have. I cannot see properly like during the day... you see yesterday... I could not see as it was raining... when I look up the sun I am affected, it is better when I walk like this (showing his face down). This started when I have sugar then gradually... the eyes were not seeing well".

These were the experiences shared by the majority of participants who were living with diabetes mellitus. Even those who did not explicitly express that they had suffered from visual problems one could determine as they were wearing vision glasses.

b. Diabetic neuropathy and pain: Neuropathy especially in the lower limbs emerged as a major category in the physiological effects theme. Participants reported that their feet were painful and could not walk properly and one participant had both lower limbs amputated.

One participant had this to say: "...I am sickly...I feel tired and sometimes ... dizziness... painful legs and cramping legs...sometimes I feel the back aching ... the body is not strong enough... it is only that... that affect me... These days it is better... it is only the cramps that trouble me... and I have difficulty in tilling the soil since it is planting season... the cramps go from the knees to the legs... and the legs feel cold at night when sleeping".

Another participant stated this: "eh... physically, I am unable to walk... I don't know if that is aging. I have difficulty climbing up the steep, I feel tight here (pointing at his legs).. and the knees become painful at times resulting to inability to walk properly... that affects me". 
One participant who was on a wheel chair had this to say: "... another ... another problem is that ... as you can see... (Low tone) I am unable to ... unable to stand up because... I am like this (pointing at her wheelchair)... because I am sitting here (meaning on wheel chair)'

The experiences of participants indicated that diabetes mellitus affected sensitivity of the extremities, especially the legs resulting to inability to walk or walk with difficulty. Swollen feet and lack of sensation were frequently reported.

c. Comorbidity: The simultaneously presence of different conditions in a client with diabetes mellitus was one of the major categories in the physiological effects theme. All participants reported more than one condition that had emerged while living with T2DM. The participants also reported that they had high blood pressure and took it as a norm to have both conditions concurrently (hypertension and diabetes mellitus).

One participant had this to say: "...oh my God... yes, I am also being treated for heart problem and ... sugar... my legs... since I started to be treated for sugar and BP (meaning Blood Pressure) my legs become swollen'

Another participant stated that: "don't say that (grinning)...I also have 'high high' (high blood pressure) my child".

This was the participant's physiological experience of living with T2DM that to have high blood pressure was a normal occurrence when you were diagnosed with diabetes mellitus.

\section{Psychological effects of living with diabetes mellitus}

A majority of participants reported sexual problems as a major category in the psychological effects of living with T2DM. Although some had pointed out that there was a lot happening to them with regard to the psychological effects that they took as part of aging and not necessarily the effects of diabetes mellitus.

Sexual dysfunction was a major complaint in almost all the male participants, whereas, none of the female participants reported it as a problem.

One male participant had this to say: "...it's just that where it ended up affecting me... it's just that... aw... (Low tone) I just look at a woman (meaning no sexual desire)...eh ... that is the only part sugar has affected me".

Another male participant stated that: "I would say that.. what I see affecting me a lot is the inability to greet the family (lack of sexual performance)...that is the thing I see affecting me...eh (low tone)".

Another male participant had this to say: "now that the sugar is high...I am not touching my wife...just nothing... nothing".

A female participant had this to say: "...oh...there is no problem with me as my husband is older than me now and is sick...the bedroom issues are things that he does not care of".

\section{Socioeconomic effects of living with diabetes mellitus}

The financial costs and travelling long distances emerged as major category in the socioeconomic effects among participants living with diabetes mellitus. Most participants reported that money was the challenge when living with the condition.

a. Financial support and costs: As the majority of the participants were either unemployed or retired they did not have sufficient income to meet their daily needs. The participants reported that the Swaziland Government needed to increase the elderly social grants to enable the participants to manage diabetes mellitus appropriately.

One participant had this to say: "you see... look at me (pointing at herself) I am disabled and this (pointing at the wheel chair) l...like when you are like me, how can they help you, like the Welfare people...they don't help us...at all".

Another participant stated that: "yes...yes...no...the Social Department must care for us...it is needed to care for us because we are at home not working...and the social grant from government...is too small... and we are not able ...to satisfy the family because as we are living, we have children...I have grand children who lost their father and their mother is not working. I am not working because I am disabled...as I am old...you see... and that makes us cry a lot...if government...if it's according to us...we will ask for an increase to our grants... to buy...foods.. to come here and to feed the orphans".

Another participant said: "we have problems with the social grant especially when you get the money from the bank...the bank charges...and as a result you are left with little money... the money does not cater for our needs...we feel it should be increased maybe we can breathe".

b. Travelling long distances: Most participants lived far away from the nearest health facility, which was more than the eight [8] km recommended by Government. Participants reported that they had to wake up early in the morning to board the first mode of transport while fasting as a prerequisite for undergoing a fasting blood glucose test which had to be performed on every followup visit.

One participant had this to say: "... my child...the issue of money...government should increase the money because right now I am staying too far...I have to get a bus to and from home...from here to home ...I pay E10... and that makes E20 with return journey. Now I have to look for food to eat."

Another one said: "...since I am coming from a far place... I wish these services could be spread to rural places...to cut down the cost of travelling now and again....because you see... we are not working". This finding reflected the need for decentralization of diabetes mellitus services.

\section{Self-management effects in living with diabetes mellitus}

a. Treatment adherence: Most participants reported that the availability of drugs in the hospital was a challenge as at times they were told that medication was out 
of stock and they had to either buy from the local pharmacy which was too costly to the majority of the participants or wait until the next follow-up visit for medication refill. One participant had this to say: “...not enough challenges... because ...as I started coming here (hospital), they give me enough pills , but at times they don't give us all the pills...they give us the available pills and other pills we buy them at the chemist... which is too costly... costly ...as we are not working".

b. Long waiting period: Emerged as another category in the therapy related effects of people living with diabetes.

One participant had this to say: "I want ...to talk something... because I need help...I need help my child...that we must get urgent attention because we have sugar, so that we can get food...in time...you see... the long queue ...now we have not eaten"

c. Knowledge: Knowledge deficit on managing T2DM emerged as a major category in the therapy related effects among persons living with diabetes mellitus.

One participant had this to say: "they do teach us at times... but in many times...ah...there was this nurse who used to teach us a lot about diabetes...but was then transferred to another hospital in Manzini... I don't know...the nurse was so good at teaching us because before...we...we collect our numbers and register...she...taught us on how to manage yourself while living with sugar".

Another participant said: "oh...these days there is nothing we get...it's been...long time since we last had teachings here... before ...they used to tell us in the morning on how to look after yourself...while living with sugar...such as avoiding walking barefooted...even the food you are supposed to eat...they no longer do it now...yes ...thank you". There is need for reviving the health education session each day to diabetic clients who come for follow-up care, because empowering clients with knowledge will enhance self-care.

\section{Discussion}

Diabetes mellitus could damage the blood vessels of the retina (diabetic retinopathy), potentially leading to blindness. Consistent with Lee and Sum [14], poor vision emerged as one of the physiological effects of living with diabetes mellitus. In accordance to Lee and Sum [14] retinopathy increases progressively with increasing duration of diabetes mellitus. The finding is also supported by Islam, Lechner, Ferrari, Froeschl, Niessen, Seissler \& Alam [15] that diabetes mellitus could lead to a variety of disabling complications, including peripheral artery disease, and visual impairment.

The American Diabetes Association [7] also concurred with the above researchers that people living with diabetes mellitus have long-term complications including retinopathy with potential loss of vision. Therefore, regular eye examination in patients suffering from diabetes mellitus is important because poor vision could lead to social isolation, an increased risk of accidents, impaired ability to monitor blood glucose, and administer insulin.
The current study revealed that neuropathy was a common complication resulting in diabetic ulcerations, pain and lower limb amputation. Consistent with Davies, Brophy, Williams and Taylor [16]; Black, Hawks and Keene [8] who revealed that most clients living with diabetes mellitus experienced peripheral neuropathy and described the symptoms as burning pain, stabbing, shooting pain, severe numbness in different body parts. At the other end of the spectrum, clients may describe a feeling of total numbness in the feet and lower leg [8], much like in the current study. In addition, muscular pain secondary to impaired motor neurons could present as night cramps, spasm or a dull ache [8].

Manschot, Biessels, Rutten, Kessels, Glipsen \& Kappelle [17] acquiesced with the above statement that peripheral and neurologic complications in adults living with T2DM generated significant reductions in patients' quality of life. The ConsensusBased Practical Guidelines for the Treatment and Prevention of Diabetic Foot [18] reported that foot complications were among the most serious and costly complications in patients suffering from diabetes mellitus. Every 30 seconds in the world a lower limb or part of it is lost due to diabetes mellitus. Amputations of all or part of a lower limb is usually preceded by a foot ulcer. This indicates that patients with T2DM need to be educated on prevention, early detection, and measures to reduce the risk of complications related to diabetes.

Persons living with diabetes mellitus may present with distressing physical symptoms. The long-term effects of distressing symptoms include interference with the individual's quality of life. According to Kalyani, Saudek, Bracati \& Selvin [19] adults living with diabetes mellitus have a high prevalence of disability attributed to T2DM related complications.

In harmony Sinclair, Conroy and Bayer [20]; Srikanth and Deedwania [21] revealed that cardiovascular disorders including hypertension were experienced simultaneously with diabetes mellitus. Sinclair, Conroy and Bayer [20] revealed that a majority of participants living with diabetes mellitus had more comorbidities compared to those in the control group. These findings suggest that specific health care interventions be designed for clients living with diabetic mellitus so as to reduce prevalence of comorbidities.

The traditional management of diabetes mellitus targets the diet, medication, and exercise, yet the psychological aspects of T2DM are overwhelming. Consistent with previous research $[22,23]$ the study revealed that the inability to achieve and maintain an erection sufficient for satisfactory sexual intercourse was distressing and was a common symptom among men living with diabetes mellitus. Diabetes mellitus has been long considered a major cause of sexual dysfunction among people living with the illness. Rosen, Wing, Schneider, Wadden, Foster, West, et al., [22] noted that in the presence of more than one disease and diabetes mellitus related complications in men living with diabetes mellitus, sexual dysfunction was aggravated. Copeland et al., [23] support the findings of the study by Rosen, et al. [22] that the risk of sexual dysfunction is higher among diabetic compared to nondiabetic men. The researchers [23] also revealed that women also 
experienced a variety of sexual dysfunction including vascular changes in the urogenital tissues affecting genital lubrication and neuropathy-mediated alterations.

Contrary to previous research [23] in the current study, sexual dysfunction was not reported among female participants. However, this may be related to that discussions on sexuality and sexual issues is viewed as a taboo in Swazi culture. Copeland, et al. [23] reported that females suffering from diabetes mellitus also experienced sexual dysfunction, much like their male counterparts. The findings by Copeland, et al. [23] suggest that health care providers should assess the psychosocial wellbeing of all adults living with diabetes mellitus. In understanding and addressing the psychosocial wellbeing of clients living with diabetes mellitus, the relationship between the client and family could be strengthened. Diabetes mellitus is a devastating chronic progressive disease associated with multiple long terms social implications which disturb the client's wellbeing and social life. It was evident from the participants that there were various socioeconomic consequences of living with diabetes mellitus. These consequences arose from insufficient funds and resources to cater for their special needs: lack of financial support from the family and insufficient social grants. Diabetes mellitus affects both individuals and their families and has an impact on economic development of a country. Diabetes mellitus changes the patient's personal situation and causes permanent health deterioration, which restricts or entirely impedes the patients' performance of activities of daily living. It also causes considerable human as well as social and economic losses resulting to poor quality of life [24]. These effects probably also disable communities and retard national economic growth.

Consistent with the WHO [8], the study finding revealed that most clients who live with diabetes mellitus were among the elderly, and resided far from health facilities. Travelling for monthly follow-up care was a challenge, as the cost for transport is continuously escalating. It also transpired from the study that at times their medications were out of stock and thus sometimes clients had to buy the medication from the pharmacy. For those clients without money the month just passed without having their daily medications.

It is then impossible for people living with diabetes to adhere to treatment as most of them could not afford to buy medication from the pharmacy and thus could result to complications. Treatment adherence then becomes a major factor in managing this chronic condition. These findings are supported by researchers [25] that adherence to medication was vital in achieving glucose control. Poor adherence to medication in clients living with diabetes mellitus could result in complications, such as medication-related weight gain and cardiovascular risk. Zhang, Chan, and Chen [26] concur with Hauber, et al. [25] on that the unavailability of medication in health facilities resulted in poor adherence among people living with diabetes mellitus. Therefore, it is imperative for health care managers to be future focused so as to avoid anti-diabetic medication from running out of stock.

In accordance with WHO [8] the costs of diabetes mellitus affected everyone, everywhere, but they were not only financially related. Intangible costs include pain, anxiety, inconvenience and generally have a great impact on the lives of clients and their families and are the most difficult to quantify. Direct costs to individuals and families include medical care, drugs, insulin and other supplies. Clients may also have to bear other personal costs, such as increased payments for health, life, and automobile insurance [8].

The findings of this study also revealed that most participants living with diabetes mellitus were not employed and this interfered with their daily needs to control the condition. It could be possible that most clients living with diabetes mellitus had poor health which might have contributed to loss of employment. Living with diabetes mellitus demands regular follow-up care and appropriate diet which they may not afford due to lack of money. This implies that the social grant for the elderly should be reviewed and probably expanded to accommodate individuals who suffer from chronic disorders including diabetes mellitus. This might enable individuals living with diabetes mellitus to maintain quality life, reduce morbidity, disability, and mortality.

Health education and counseling are fundamental building blocks for self-management. Inorder for the diabetics to effectively manage their illness they need to be empowered with knowledge, and skills. In harmony with George and Thomas [9], the study findings showed that most participants had knowledge deficit about their disorder, diabetes mellitus. According to Hauber, Mohamed, Johnson and Farley [25] successful education does not only impart knowledge but also empowers and motivates individuals to utilize knowledge and apply practical skills in self-management. George and Thomas [9] found that knowledge gaps and negative attitude regarding diabetes mellitus self-management were common among participants. However, the current study did not research on the participants attitudes towards self-management. Furthermore, George and Thomas [9] revealed that most clinicians and researchers advocated that clients needed to be taught skills on self- management to become reliable, capable and responsible to take care of self. This implies that tailored programs for clients living with diabetes mellitus be developed in order to improve their knowledge and self-management skills.

\section{Recommendations}

Based on the study findings it is recommended that:

1. The Ministry of Health consider decentralizing services for managing non-communicable diseases such as diabetes mellitus to facilitate client access to care.

2. Health care providers should empower clients living with diabetes mellitus and their families on knowledge and skills essential in self-management.

3. Health care providers need to encourage clients living with diabetes mellitus to have back-yard gardens so as to improve their diet. 
4. Health care providers need to monitor clients living with diabetes mellitus for diabetes mellitus related complications, this will enable early detection, timeous intervention, and improved patient outcomes.

5. The Swaziland Government need to consider expanding social grants to those clients living with chronic diseases including diabetes mellitus.

\section{Limitations of the study}

The study was limited to adults living with T2DM aged between 49-79 years only. The study design confined us to a small sample size. The results may be generalized with caution to other age groups of individuals living with diabetes mellitus in Swaziland. The available literature utilized was mostly from United States of America which is in a developed continent.

\section{Conclusion}

The study revealed that adults living with T2DM experiences distressing physiological, psychological, socio-economic, and self-management challenges related to their disorder. Adults living with diabetes mellitus require monitoring for early detection of complications, which may result in improved patient outcomes. The clients need to be empowered with knowledge and skills on managing diabetes mellitus so as to achieve blood glucose control and reduce the risk of developing T2DM related complications.

\section{References}

1. Fadare J, Olamoyegun M, Gbadegesin B A (2015) Medical adherence and direct treatment cost among diabetes patients attending a tertiary health care facility in Ogbomosho, Nigeria. Malawi Medical Journal 27: 65-70. Link: https://bit.ly/3IWtQ9P

2. Smeltzer CS, Bare BG, Hinkle JL, Cheever KH (2010) Brunner and Suddarth textbook of medical surgical nursing. $12^{\text {th }}$ edition. Lippincott: Raven. Link: https://bit.ly/3c3xyuo

3. Nielsen J, Bahendeka SK, Gregg EW, Whyte SR, Bygbjerg IC, et al. (2015). A comparison of cardiometabolic risk factors in households in rural Uganda with and without a resident with Type 2 diabetes, 2012-2013. Prevention of chronic disease. Link: https://bit.ly/3C2R3gh

4. Gambert SR, Pinkstaff S (2006) Emerging epidemic: diabetes in older adults: demography, economic, impact \& Pathophysiology. Diabetes Spectrum 19: 221-228. Link: https://bit.ly/3B3ZhDk

5. Kneck A, Klang B, Fagerberg I (2011) Learning to live with illness: experiences of persons with recent diagnoses of diabetes mellitus. Scandavian Journal of Caring Sciences 25: 558-566. Link: https://bit.ly/3G7dlu6

6. International Diabetes Federation [IDF] (2007) Diabetes Atlas. $3^{\text {rd }}$ edition. Link: https://bit.ly/3jnnoXO

7. American Diabetes \& Association (ADA) (2007) Repor $t$ of the expert committee on the diagnosis and classification of diabetes mellitus. Diabetes Care 26: 5-20. Link: https://bit.ly/3niL6Wt

8. Black JM, Hawks JH, Keene AM (2009) Medical-Surgical Nursing: clinical management of positive outcome ( $8^{\text {th }}$ Edition). St. Louis: Sounders Elsevier. Link: https://bit.ly/3poeNry
9. George SR, Thomas SP (2010) Lived experiences of diabetes among older, rural people. Journal of Advanced Nursing 66: 1092-1100. Link: https://bit.ly/3B6bcka

10. World Health Organization Report (2008) Primary Health Care. Link: https://bit.ly/3B4e6pH

11. Swazialnd STEPS Survey Fact Sheet (2007) Maintenance break. Link: https://bit.ly/3aXHaVa

12. Swaziland Central Statistics Office Report (2007) Mbabane, Swaziland. Link: https://bit.ly/3E2OdbD

13. Swaziland Ministry of Health Report (2007) Ministry of health and socia welfare. Link: https://bit.ly/2XxT7h8

14. Lee KM, Sum WM (2011) Prevalence of diabetic retinopathy in patients with diabetes mellitus. Clinical Experimental Optometry 94: 371-375. Link: https://bit.ly/3vwUh9i

15. Islam S M, Lechner A, Ferrari U, Froeschl G, Niessen L W, et al. (2013) Social and economic impact of diabetics in Bangladesh: protocol for a case-control study. BMC Public Health 13. Link: https://bit.ly/30Rpitv

16. Davies M, Brophy S, Williams R, Taylor A (2006) The prevalence, severity, and impact of painful diabetic peripheral neuropathy in type 2 diabetes. Diabetes Care 29: 1518-1522. Link: https://bit.ly/3aXUDML

17. Manschot SM, Biessels GJ, Rutten GE, Kessels RC, Glispen WH, et al. (2007) Peripheral and central neurologic complications in type 2 diabetes. Journal of Neurological Sciences 264: 157-162. Link: https://bit.ly/3B1D74P

18. The Consensus-Based Practical Guidelines for the Treatment and Prevention of Diabetic Foot (2008)

19. Kalyani RR, Saudek CD, Brancati FL, Selvin E (2010) Association of diabetes comorbidities and $\mathrm{ACl}$ with functional disability in older adults. Diabetes Care 33: 1055-1060. Link: https://bit.ly/3jn7i0t

20. Sinclair AJ, Conroy SP, Bayer AJ (2008) Impact of diabetes on physical function in older people. Diabetes Care 31: 233-235. Link: https://bit.ly/30GLwxX

21. Srikanth S, Deedwania P (2011) Primary and secondary prevention strategy for cardiovascular disease in diabetes mellitus. Cardiology Clinics, 29: 47-70. Link: https://bit.ly/3E58NrJ

22. Rosen RC, Wing RR, Schneider S, Wadden TA, Foster GD, et al. (2009) Erectile dysfunction in type 2 diabetic men: relationship to exercise fitness and cardiovascular risk factors. Journal of Sexual Medicine 6: 1414-1422. Link: https://bit.ly/3B23oQo

23. Copeland KL, Brown JS, Creasman JM Van Den Eeden SK, Subak LL, et al. (2012) Diabetes mellitus and sexual function in middle-aged and older women. Obstetrics and Gynecology 120: 331-340. Link: https://bit.ly/3G0AB2m

24. Golicki D, Dudzinska M, Zwolak A, Tarach JS (2015) Quality of life in patients with type 2 diabetes in Poland-comparison with the general population using the EQ-5D questionnaire. Advanced Clinical Exp Med 24: 139-146. Link: https://bit.ly/2Z8EIZg

25. Hauber AB, Mohamed AF, Johnson FR, Falvey H (2009) Education and psychological aspects treatment preferences and medication adherence of people with Type 2 diabetes using oral glucose-lowering agents. Diabetic Medicine 26: 416-424. Link: https://bit.ly/3B1FEvT

26. Zhang C, Chen Y, Chen W (2007) Association of psychosocial factors with anxiety and depression symptoms in Chinese patients with type 2 diabetes. Diabetes Research and Clinical Practice 79: 523-530. Link: https://bit.ly/3bdFAPj

Citation: Khumalo PP, Sebego M, Vilakati CZ, Mkhabela MSP, Mathunjwa-Dlamini TR (2021) The experience of living with diabetes mellitus. Arch Community Med Public Health 7(3): 205-211. DOI: https://dx.doi.org/10.17352/2455-5479.000163 